\title{
Common fixed point theorems for $(\psi, \phi)$-weak nonlinear contraction in partially ordered sets
}

\author{
Madjid Eshaghi Gordji $1^{*}$, Hamid Baghani ${ }^{2}$ and Gwang Hui Kim ${ }^{3^{*}}$
}

\author{
* Correspondence: madjid. \\ eshaghi@gmail.com; \\ ghkim@kangnam.ac.kr \\ 'Department of Mathematics, \\ Semnan University, P.O. Box 35195- \\ 363, Semnan, Iran \\ ${ }^{3}$ Department of Mathematics, \\ Kangnam University, Yongin, \\ Gyeonggi 446-702, Korea \\ Full list of author information is \\ available at the end of the article
}

\begin{abstract}
The purpose of this article is to present some fixed point theorems for $(\psi, \phi)$-weak contractive mappings in a complete metric space endowed with a partial order. As an application of the main result, we give an existence theorem for the solution of a periodic boundary value problem.
\end{abstract}

2000 Mathematics Subject Classification: 47H10.

Keywords: fixed point, weakly contractive mapping, partially ordered set

\section{Introduction and preliminaries}

It is well known that the Banach Contraction Principle has been generalized in various directions. Alber and Guerre-Delabrere [1] introduced the concept of weak contractions in Hilbert spaces and proved the corresponding fixed point result. Rhoades [2] showed that the result of Alber et al. is also valid in complete metric spaces. Weakly contractive mappings have been used in a number of subsequent articles (let us mention articles [3-10]) to establish various fixed point and common fixed point theorems. In particular, recent results of Zhang and Song [9] and Doric [10] are among the most general ones. Also, some applications were obtained, in particular when dealing with differential and matrix equations.

Existence of fixed point in partially ordered sets has been considered recently in [11-25]. Tarski's theorem is used in [26] to show the existence of solutions for fuzzy equations and in [27] to prove existence theorems for fuzzy differential equations. In $[24,25,27]$ some applications to matrix equations and to ordinary differential equations are presented. In [28-32], it is proved some fixed point theorems for a mixed monotone mapping in a metric space endowed with partial order and the authors apply their results to problems of existence and uniqueness of solutions for some boundary value problems [26,32]. We begin by stating the result of Rhoades [2] after the following definition.

A mapping $f: X \rightarrow X$, where $(X, d)$ is a metric space, is said to be weakly contractive if

$$
d(f x, f y) \leq d(x, y)-\varphi(d(x, y))
$$

where $x, y \in X$ and $\varphi:[0, \infty) \rightarrow[0, \infty)$ is a continuous and nondecreasing function such that $\varphi(t)=0$ if and only if $t=0$. If one takes $\phi(t)=(1-k) t$, where $0 \leq k<1$, then (1.1) reduces to the contractivity condition

(c) 2012 Gordji et al; licensee Springer. This is an Open Access article distributed under the terms of the Creative Commons Attribution License (http://creativecommons.org/licenses/by/2.0), which permits unrestricted use, distribution, and reproduction in any medium, provided the original work is properly cited. 


$$
d(f x, f y) \leq k d(x, y)
$$

Theorem 1.1. ([2]) Let $(X, d)$ be a complete metric space, and $f: X \rightarrow X$ be a weakly contractive mapping. Then $f$ has a unique fixed point.

Weak inequalities of the above type have been used to establish fixed point results in a number of subsequent articles. For example, Zhang and Song [9] used generalized $\phi$-weak contraction which is defined for two mappings and gave conditions for existence of a common fixed point.

Theorem 1.2. ([9]) Let $(X, d)$ be a complete metric space, and $f, g: X \rightarrow X$ be two mappings such that for all $x, y \in X$

$$
d(f x, g y) \leq M(x, y)-\varphi(M(x, y))
$$

where $\phi:[0, \infty) \rightarrow[0, \infty)$ is lower semi-continuous functions with $\phi(t)>0$ for $t \in(0$, $\infty), \phi(0)=0$, and

$$
M(x, y)=\max \left\{d(x, y), d(x, f x), d(y, g y), \frac{1}{2}(d(x, g y)+d(y, f x))\right\} .
$$

Then there exists a unique fixed point $u \in X$ such that $u=f u=g u$.

Recently, Doric [10] extended the result of Zhang and Song using a pair of functions $\psi$ and $\phi$. He proved the following theorem.

Theorem 1.3. ([10]) Let $(X, d)$ be a complete metric space, and $f, g: X \rightarrow X$ be two mappings such that

$$
\psi(d(f x, g y)) \leq \psi(M(x, y))-\varphi(M(x, y))
$$

for all $x, y \in X$, where

(i) $\psi:[0, \infty) \rightarrow[0, \infty)$ is a continuous and nondecreasing function such that $\psi(t)=0$ if and only if $t=0$.

(ii) $\phi:[0, \infty) \rightarrow[0, \infty)$ is a lower semi-continuous function such that $\phi(t)=0$ if and only if $t=0$.

(iii) $M$ is defined by (1.2).

Then there exists a unique fixed point $u \in X$ such that $u=f u=g u$.

When fixed point problems in partially ordered metric spaces are concerned, first results were obtained by Ran and Reurings [25], and then by Nieto and Lopez [14]. The following two versions of the fixed point theorem were proved in these articles.

Theorem 1.4. $([14,25])$ Let $(X, \subseteq$ be a partially ordered set and let $d$ be a metric on $X$ such that $(X, d)$ is a complete metric space. Let $f: X \rightarrow X$ be a nondecreasing map $w$. $r . t$. ㄷ. Suppose that the following conditions hold:

(i) There exists $k \in(0,1)$ such that $d(f x, f y) \leq k d(x, y)$, for all $x, y \in X$ with $y \sqsubseteq x$;

(ii) there exists $x_{0} \in X$ such that $x_{0} \subseteq f x_{0}$.

Then in each of the following two cases the mappings $f$ has at least one fixed point.

$\left(\tau_{1}\right) f$ is continuous, or

$\left(\tau_{2}\right)$ if a nondecreasing sequence $\left\{x_{n}\right\}$ converges to $x$, then $x_{n} \subseteq x$ for all $n$.

Results on weakly contractive mappings in such spaces were obtained by Harjani and Sadarangani in [7]. We state one of their results.

Theorem 1.5. ([7]) Let $(X$, ㄷ) be a partially ordered set and let $d$ be a metric on $X$ such that $(X, d)$ is a complete metric space. Let $f: X \rightarrow X$ be a nondecreasing map w.r. $t$. ᄃ such that for every two comparable elements $x, y \in X$, 


$$
d(f x, f y) \leq d(x, y)-\varphi(d(x, y)),
$$

(i) $\phi:[0, \infty) \rightarrow[0, \infty)$ is similar to the control function $\phi$ of Theorem 1.3.

(ii) there exists $x_{0} \in X$ such that $x_{0} \subseteq f x_{0}$.

Then in each of the following two cases the mappings $f$ has at least one fixed point.

$\left(\tau_{1}\right) f$ is continuous, or

$\left(\tau_{2}\right)$ if a nondecreasing sequence $\left\{x_{n}\right\}$ converges to $x$, then $x_{n}$ 드 $x$ for all $n$.

\section{Main results}

Let $(X, \subseteq)$ be a partially ordered set. A pair $(f, g)$ is said to be weakly increasing if $f x$ 드 $g f x$ and $g x \subseteq f g x$ for all $x \in X$. There are examples (see [4]) when neither of such mappings $f, g$ is nondecreasing w.r.t. 드. In particular, the pair $\left(f, i_{X}\right)\left(i_{x}\right.$ the identy function) is weakly increasing if and only if $x \subseteq f x$ for each $x \in X$.

Theorem 2.1. Let $(X, \subseteq)$ be a partially ordered set and let $d$ be a metric on $X$ such that $(X, d)$ is a complete metric space, and let $f, g: X \rightarrow X$ be two weakly increasing mappings such that for every two comparable elements $x, y \in X$,

$$
\psi(d(f x, g y)) \leq \psi(M(x, y))-\varphi(\psi(M(x, y)))+\theta(N(x, y)),
$$

where

(i) $\psi:[0, \infty) \rightarrow[0, \infty)$ is a continuous and nondecreasing function such that $\psi(t)=0$ if and only if $t=0$ and also $\lim \sup _{s \rightarrow 0^{+}} \frac{s}{\psi(s)}<\infty$.

(ii) $\phi:[0, \infty) \rightarrow[0, \infty)$ is a lower semi-continuous function such that $\phi(t)=0$ if and only if $t=0$ and also for any sequence $\left\{t_{n}\right\}$ with $\lim _{n \rightarrow \infty} t_{n}=0$, there exists $k \in(0,1)$ and $n_{0} \in \mathbb{N}$, such that $\phi\left(t_{n}\right) \geq k t_{n}$ for each $n \geq n_{0}$.

(iii) $\theta:[0, \infty) \rightarrow[0, \infty)$ is a continuous function such that $\theta(t)=0$ if and only if $t=0$.

(iv) $M$ is defined by $(1.2)$ and $N(x, y)=\min \{d(y, f x), d(x, g y)\}$.

Then in each of the following two cases the mappings $f$ and $g$ have at least one common fixed point.

$\left(\tau_{1}\right) f$ or $g$ is continuous, or

$\left(\tau_{2}\right)$ if a nondecreasing sequence $\left\{x_{n}\right\}$ converges to $x$, then $x_{n} \sqsubseteq x$ for all $n$.

Proof. Step 1. Using that the pair of functions $(f, g)$ is weakly increasing, we can construct inductively, starting with arbitrary $x_{0} \in X$, a sequence $\left\{x_{n}\right\}$ such that $x_{n} \subseteq x_{n+1}$. Namely, denoted:

$$
\begin{aligned}
& x_{1}=f x_{0} \sqsubseteq g f x_{0}=g x_{1}, \\
& x_{2}=g x_{1} \sqsubseteq f g x_{1}=f x_{2}, \\
& x_{3}=f x_{2} \sqsubseteq g f x_{2}=g x_{3}, \\
& \ldots
\end{aligned}
$$

and in general, $x_{2 n+1}=f x_{2 n}$ and $x_{2 n+2}=g x_{2 n+1}$ for all $n \in \mathbb{N}$.

Suppose first that $x_{n_{0}}=x_{n_{0}+1}$ for some $n_{0}$. Then, the sequence $\left\{x_{n}\right\}$ is constant for $n \geq$ $n_{0}$.

Indeed, let $n_{0}=2 k$. Then $x_{2 k}=x_{2 k+1}$ and we obtain from (2.1) that

$$
\begin{aligned}
\psi\left(d\left(x_{2 k+1}, x_{2 k+2}\right)\right) & =\psi\left(d\left(f x_{2 k}, g x_{2 k+1}\right)\right) \\
& \leq \psi\left(M\left(x_{2 k}, x_{2 k+1}\right)\right)-\varphi\left(\psi\left(M\left(x_{2 k}, x_{2 k+1}\right)\right)\right)+\theta\left(N\left(x_{2 k}, x_{2 k+1}\right)\right),
\end{aligned}
$$


where

$$
\begin{aligned}
M\left(x_{2 k}, x_{2 k+1}\right) & =\max \left\{d\left(x_{2 k}, x_{2 k+1}\right), d\left(x_{2 k}, f x_{2 k}\right), d\left(x_{2 k+1}, g x_{2 k+1}\right),\right. \\
& \left.\frac{1}{2}\left(d\left(x_{2 k}, g x_{2 k+1}\right)+d\left(x_{2 k+1}, f x_{2 k}\right)\right)\right\} \\
& =\max \left\{0,0, d\left(x_{2 k+1}, x_{2 k+2}\right), \frac{1}{2}\left(d\left(x_{2 k}, x_{2 k+2}\right)+0\right)\right\} \\
& =\max \left\{d\left(x_{2 k+1}, x_{2 k+2}\right), \frac{1}{2} d\left(x_{2 k}, x_{2 k+2}\right)\right\} \\
& =d\left(x_{2 k+1}, x_{2 k+2}\right),
\end{aligned}
$$

and

$$
N\left(x_{2 k}, x_{2 k+1}\right)=\min \left\{d\left(f x_{2 k}, x_{2 k+1}\right), d\left(g x_{2 k+1}, x_{2 k}\right)\right\}=0 .
$$

Now from (2.2), we get that

$$
\psi\left(d\left(x_{2 k+1}, x_{2 k+2}\right)\right) \leq \psi\left(d\left(x_{2 k+1}, x_{2 k+2}\right)\right)-\varphi\left(\psi\left(d\left(x_{2 k+1}, x_{2 k+2}\right)\right)\right),
$$

and so $\psi\left(d\left(x_{2 k+1}, x_{2 k+2}\right)\right) \leq 0$ and $x_{2 k+1}=x_{2 k+2}$. Similarly, if $n_{0}=2 k+1$ one easily obtains that $x_{2 k+2}=x_{2 k+3}$ and the sequence $\left\{x_{n}\right\}$ is constant (starting from some $n_{0}$ ) and $x_{n_{0}}$ is common fixed point of $f$ and $g$.

Suppose now that $d\left(x_{n}, x_{n+1}\right)>0$ for each $n$. We shall show that for each $n=0,1, \ldots$,

$$
d\left(x_{2 n+1}, x_{n+2}\right) \leq M\left(x_{2 n}, x_{2 n+1}\right)=d\left(x_{2 n}, x_{2 n+1}\right),
$$

and

$$
d\left(x_{2 n+3}, x_{n+2}\right) \leq M\left(x_{2 n+2}, x_{2 n+1}\right)=d\left(x_{2 n+2}, x_{2 n+1}\right) .
$$

It is clear that $N\left(x_{2 n}, x_{2 n+1}\right)=0$ and $N\left(x_{2 n+2}, x_{2 n+1}\right)=0$, for all $n \in \mathbb{N}$. Using condition (2.1), since $x_{2 n}$ and $x_{2 n+1}$ are comparable, we obtain that

$$
\begin{aligned}
\psi\left(d\left(x_{2 n+1}, x_{2 n+2}\right)\right) & =\psi\left(d\left(f x_{2 n}, g x_{2 n+1}\right)\right) \\
& \leq \psi\left(M\left(x_{2 n}, x_{2 n+1}\right)\right)-\varphi\left(\psi\left(M\left(x_{2 n}, x_{2 n+1}\right)\right)\right)+\theta\left(N\left(x_{2 n}, x_{2 n+1}\right)\right) \\
& \leq \psi\left(M\left(x_{2 n}, x_{2 n+1}\right)\right)
\end{aligned}
$$

and since the control function $\psi$ is nondecreasing, it follows that

$$
d\left(x_{2 n+1}, x_{2 n+2}\right) \leq M\left(x_{2 n}, x_{2 n+1}\right) .
$$

Hence

$$
\begin{aligned}
M\left(x_{2 n}, x_{2 n+1}\right) & =\max \left\{d\left(x_{2 n}, x_{2 n+1}\right), d\left(x_{2 n}, f x_{2 n}\right), d\left(x_{2 n+1}, g x_{2 n+1}\right),\right. \\
& \left.\frac{1}{2}\left(d\left(x_{2 n}, g x_{2 n+1}\right)+d\left(x_{2 n+1}, f x_{2 n}\right)\right)\right\} \\
& =\max \left\{d\left(x_{2 n}, x_{2 n+1}\right), d\left(x_{2 n}, x_{2 n+1}\right), d\left(x_{2 n+1}, x_{2 n+2}\right), \frac{1}{2} d\left(x_{2 n}, x_{2 n+2}\right)\right\} \\
& \leq \max \left\{d\left(x_{2 n}, x_{2 n+1}\right), d\left(x_{2 n+1}, x_{2 n+2}\right), \frac{1}{2}\left(d\left(x_{2 n}, x_{2 n+1}\right)+d\left(x_{2 n+1}, x_{2 n+2}\right)\right)\right\} \\
& \leq \max \left\{d\left(x_{2 n}, x_{2 n+1}\right), d\left(x_{2 n+1}, x_{2 n+2}\right)\right\} .
\end{aligned}
$$

If $d\left(x_{2 n+1}, x_{2 n+2}\right) \geq d\left(x_{2 n}, x_{2 n+1}\right)$, then it follows from the last inequality and (2.6) that $M\left(x_{2 n}, x_{2 n+1}\right)=d\left(x_{2 n+1}, x_{2 n+2}\right)$ and condition (2.5) implies that 


$$
\begin{aligned}
\psi\left(d\left(x_{2 n+1}, x_{2 n+2}\right)\right) & =\psi\left(d\left(f x_{2 n+}, g x_{2 n+1}\right)\right) \\
& \leq \psi\left(d\left(x_{2 n+1}, x_{2 n+2}\right)\right)-\varphi\left(\psi\left(d\left(x_{2 n+1}, x_{2 n+2}\right)\right)\right)
\end{aligned}
$$

which is only possible when $d\left(x_{2 n+1}, x_{2 n+2}\right)=0$, it is a contradiction. Hence, $d\left(x_{2 n+1}\right.$, $\left.x_{2 n+2}\right) \leq d\left(x_{2 n}, x_{2 n+1}\right)$ and $M\left(x_{2 n}, x_{2 n+1}\right) \leq d\left(x_{2 n}, x_{2 n+1}\right)$. By definition, $M\left(x_{2 n}, x_{2 n+1}\right) \geq d$ $\left(x_{2 n}, x_{2 n+1}\right),(2.3)$ is proved for $d\left(x_{2 n+1}, x_{2 n+2}\right)$. In a Similar way, one can obtain that

$$
d\left(x_{2 n+3}, x_{2 n+2}\right) \leq M\left(x_{2 n+2}, x_{2 n+1}\right)=d\left(x_{2 n+2}, x_{2 n+1}\right) .
$$

So, (2.3) and (2.4) holds for each $n \in \mathbb{N}$.

It follows that the sequence $\left\{d\left(x_{n}, x_{n+1}\right)\right\}$ is nondecreasing. Let $\lim _{n \rightarrow \infty} d\left(x_{n}, x_{n+1}\right)=$ $d^{*}$, for some $d^{*} \geq 0$ then

$$
\lim _{n \rightarrow \infty} M\left(x_{2 n}, x_{2 n+1}\right)=d^{*},
$$

and

$$
\lim _{n \rightarrow \infty} M\left(x_{2 n+2}, x_{2 n+1}\right)=d^{*} .
$$

Suppose that $d^{*}>0$. We have

$$
\psi\left(d\left(x_{2 n+1}, x_{2 n+2}\right)\right) \leq \psi\left(M\left(x_{2 n}, x_{2 n+1}\right)\right)-\varphi\left(\psi\left(M\left(x_{2 n}, x_{2 n+1}\right)\right)\right) .
$$

Passing to the (upper) limit when $n \rightarrow \infty$, it follows that

$$
\psi\left(d^{*}\right) \leq \psi\left(d^{*}\right)-\liminf _{n \rightarrow \infty} \varphi\left(\psi\left(M\left(x_{2 n}, x_{2 n+1}\right)\right)\right) \leq \psi\left(d^{*}\right)-\varphi\left(\psi\left(d^{*}\right)\right),
$$

i.e. $\psi\left(d^{*}\right) \leq 0$. Using the properties of control functions, we get that $d^{*}=0$ which is a contradiction. We conclude that $\lim _{n \rightarrow \infty} d\left(x_{n}, x_{n+1}\right)=0$.

Step 2. Now we show that $\left\{x_{n}\right\}$ is a Cauchy sequence in $X$. Since

$$
\lim _{n \rightarrow \infty} \psi\left(M\left(x_{2 n}, x_{2 n+1}\right)\right)=0, \lim _{n \rightarrow \infty} \psi\left(M\left(x_{2 n+2}, x_{2 n+1}\right)\right)=0
$$

then by the property of $\phi$ there exists $k \in(0,1)$ and $n_{0} \in \mathbb{N}$ such that

$$
\begin{gathered}
\varphi\left(\psi\left(M\left(x_{2 n}, x_{2 n+1}\right)\right)\right) \geq k \psi\left(M\left(x_{2 n}, x_{2 n+1}\right)\right), \\
\varphi\left(\psi\left(M\left(x_{2 n+2}, x_{2 n+1}\right)\right)\right) \geq k \psi\left(M\left(x_{2 n+2}, x_{2 n+1}\right)\right),
\end{gathered}
$$

for all $n \geq n_{0}$. For any natural number $n \geq n_{0}$, if $n$ is even, we have

$$
\begin{aligned}
\psi\left(d\left(x_{2 n+1}, x_{2 n+2}\right)\right) & =\psi\left(d\left(f x_{2 n}, g x_{2 n+1}\right)\right) \\
& \leq \psi\left(M\left(x_{2 n}, x_{2 n+1}\right)\right)-\varphi\left(\psi\left(M\left(x_{2 n}, x_{2 n+1}\right)\right)\right) \\
& \leq(1-k) \psi\left(d\left(x_{2 n}, x_{2 n+1}\right)\right)
\end{aligned}
$$

and similarly

$$
\begin{aligned}
\psi\left(d\left(x_{2 n}, x_{2 n+1}\right)\right) & =\psi\left(d\left(f x_{2 n}, g x_{2 n-1}\right)\right) \\
& \leq \psi\left(M\left(x_{2 n}, x_{2 n-1}\right)\right)-\varphi\left(\psi\left(M\left(x_{2 n}, x_{2 n-1}\right)\right)\right) \\
& \leq(1-k) \psi\left(d\left(x_{2 n}, x_{2 n-1}\right)\right) .
\end{aligned}
$$

Hence, for all $n \geq n_{0}$, we have

$$
\begin{gathered}
\psi\left(d\left(x_{n}, x_{n+1}\right)\right) \leq(1-k) \psi\left(d\left(x_{n}, x_{n-1}\right)\right) . \\
\sum_{1}^{\infty} \psi\left(d\left(x_{n}, x_{n+1}\right)\right) \leq \sum_{1}^{n_{0}} \psi\left(d\left(x_{n}, x_{n+1}\right)\right)+\sum_{1}^{\infty}(1-k)^{n} \psi\left(d\left(x_{n_{0}}, x_{n_{0}+1}\right)\right)<\infty .
\end{gathered}
$$


Since

$$
\limsup _{n \rightarrow \infty} \frac{d\left(x_{n}, x_{n+1}\right)}{\psi\left(d\left(x_{n}, x_{n+1}\right)\right)} \leq \limsup _{s \rightarrow 0^{+}} \frac{s}{\psi(s)}<\infty
$$

then $\sum_{1}^{\infty} d\left(x_{n}, x_{n+1}\right)<\infty$. This shows that $\left\{x_{n}\right\}$ is a Cauchy sequence. Since $(X, d)$ is a complete metric space, then there exists a $z \in X$ such that $\lim _{n \rightarrow \infty} x_{n}=z$.

Step 3. We have to prove that $z$ is a common fixed point of $f$ and $g$. We shall distinguish the case $\left(\tau_{1}\right)$ and $\left(\tau_{2}\right)$ of the theorem.

$\left(\tau_{1}\right)$ Suppose that the mapping $g$ is continuous. Since $x_{2 n+1} \rightarrow z$, we obtain that $x_{2 n+2}$ $=g x_{2 n+1} \rightarrow g z$. On the other hand, $x_{2 n+2} \rightarrow z$ (as a subsequence of $\left\{x_{n}\right\}$ ). It follows that $g z=z$. To prove $f z=z$, using $z$ 드 , we can put $x=y=z$ in (2.1) and obtain that

$$
\begin{aligned}
& \psi(d(f z, g z)) \leq \psi(M(z, z))-\varphi(\psi(M(z, z)))+\theta(N(z, z)), \text { where } \\
& \begin{aligned}
M(z, z) & =\max \left\{d(z, z), d(z, f z), d(z, g z), \frac{1}{2}(d(z, g z)+d(z, f z))\right\} \\
= & \max \left\{0, d(z, f z), 0, \frac{1}{2} d(z, f z)\right\}=d(z, f z),
\end{aligned}
\end{aligned}
$$

and

$$
N(z, z)=\min \{d(z, f z), d(z, g z)\}=0 .
$$

Hence, $\psi(d(f z, z)) \leq \psi(d(z, f z))-\phi(\psi(d(z, f z)))$ it follows that $z=f z$.

The proof is similar if $f$ is continuous.

$\left(\tau_{2}\right)$ Suppose that the condition $\left(\tau_{2}\right)$ of the theorem holds. The sequence $\left\{x_{n}\right\}$ is nondecreasing w.r.t. $\subseteq$ and it follows that $x_{n} \subseteq z$. Take $x=x_{2 n}$ and $y=z$, which are comparable in (2.1) to obtain that

$$
\psi\left(d\left(f x_{2 n}, g_{z}\right)\right) \leq \psi\left(M\left(x_{2 n}, z\right)\right)-\varphi\left(\psi\left(M\left(x_{2 n}, z\right)\right)\right)+\theta\left(N\left(x_{2 n}, z\right)\right),
$$

where

$$
\begin{aligned}
M\left(x_{2 n}, z\right)= & \max \left\{d\left(x_{2 n}, z\right), d\left(x_{2 n}, f x_{2 n}\right), d(z, g z), \frac{1}{2}\left(d\left(x_{2 n}, g z\right)+d\left(z, f x_{2 n}\right)\right)\right\} \\
\rightarrow & \max \left\{0,0, d(z, g z), \frac{1}{2} d(z, g z)\right\}=d(z, g z), \\
& N\left(x_{2 n}, z\right)=\min \left\{d\left(x_{2 n}, g z\right), d\left(z, f x_{2 n}\right)\right\} \rightarrow 0 .
\end{aligned}
$$

Now, passing to the limit when $n \rightarrow \infty$ in (2.7), we get

$$
\psi(d(z, g z)) \leq \psi(d(z, g z))-\varphi(\psi(d(z, g z)))
$$

wherefrom it follows that $z=g z$.

To prove $f z=z$, using $z$ 드 we can put $x=y=z$ in (2.1) and obtain that $\psi(d(f z, g z))$ $\leq \psi(M(z, z))-\phi(\psi(M(z, z)))+\theta(N(z, z))$, where

$$
\begin{aligned}
M(z, z) & =\max \left\{d(z, z), d(z, f z), d(z, g z), \frac{1}{2}(d(z, g z)+d(z, f z))\right\} \\
& =\max \left\{0, d(z, f z), 0, \frac{1}{2} d(z, f z)\right\}=d(z, f z),
\end{aligned}
$$


and

$$
N(z, z)=\min \{d(z, f z), d(z, g z)\}=0 .
$$

Hence, $\psi(d(f z, z)) \leq \psi(d(z, f z))-\phi(\psi(d(z, f z)))$ it follows that $z=f z$.

Theorem 2.2. Let $(X$, ㄷ) be a partially ordered set and let $d$ be a metric on $X$ such that $(X, d)$ is a complete metric space, and $f: X \rightarrow X$ be a nondecreasing map such that $x_{0} \subseteq f x_{0}$ for some $x_{0} \in X$, and for every two comparable elements $x, y \in X$,

$$
\psi(d(f x, f y)) \leq \psi(M(x, y))-\varphi(\psi(M(x, y)))
$$

where

(i) $\psi:[0, \infty) \rightarrow[0, \infty)$ is a continuous and nondecreasing function such that $\psi(t)=0$ if and only if $t=0$ and also $\lim \sup _{s \rightarrow 0^{+}} \frac{s}{\psi(s)}<\infty$.

(ii) $\phi:[0, \infty) \rightarrow[0, \infty)$ is a lower semi-continuous function such that $\phi(t)=0$ if and only if $t=0$ and also for any sequence $\left\{t_{n}\right\}$ with $\lim _{n \rightarrow \infty} t_{n}=0$, there exists $k \in(0,1)$ and $n_{0} \in \mathbb{N}$, such that $\phi\left(t_{n}\right) \geq k t_{n}$ for each $n \geq n_{0}$.

(iii)

$$
M(x, y)=\max \left\{d(x, y), d(x, f x), d(y, f y), \frac{1}{2}(d(x, f y)+d(y, f x))\right\} .
$$

Then in each of the following two cases the mappings $f$ has fixed point.

$\left(\tau_{1}\right) f$ is continuous, or

$\left(\tau_{2}\right)$ if a nondecreasing sequence $\left\{x_{n}\right\}$ converges to $x$, then $x_{n} \sqsubseteq x$ for all $n$.

Theorem 2.3. Let all the conditions of Theorem 2.2 be fulfilled and let the following condition hold:

$A$ : For arbitrary two points $x, y \in X$, there exists $z \in X$, which is comparable with both $x$ and $y$ and $z$ ㄷ․ Then the fixed point of $f$ is unique.

Proof. Let $z$ and $y$ be two fixed points of $f$. Consider the following two cases.

Case 1. $z$ and $y$ are comparable. Then we can apply condition (2.8) to obtain that

$$
\psi(d(y, z))=\psi(d(f y, f z)) \leq \psi(M(y, z))-\varphi(\psi(M(y, z))) .
$$

Where

$$
M(z, y)=\max \left\{d(z, y), d(z, f z), d(y, f y), \frac{1}{2}(d(y, f z)+d(z, f y))\right\}=d(z, y),
$$

and hence

$$
\begin{aligned}
\psi(d(y, z)) & =\psi(d(f y, f z)) \leq \psi(M(y, z))-\varphi(\psi(M(y, z))) \\
& =\psi(d(z, y))-\varphi(\psi(d(z, y)))
\end{aligned}
$$

which implies that $z=y$.

Case 2. Suppose that $z$ and $y$ are not comparable. Choose an element $x \in X$ comparable with both of them and $x \sqsubseteq f x$. Then also $z=f^{n} z$ and is comparable with $f^{n} x$, for each $n$, since $f$ is nondecreasing. Applying (2.8) one obtains that

$$
\begin{aligned}
\psi\left(d\left(z, f^{n} x\right)\right) & =\psi\left(d\left(f f^{n-1} z, f f^{n-1} x\right)\right) \\
& \leq \psi\left(M\left(f^{n-1} z, f^{n-1} x\right)\right)-\varphi\left(\psi\left(M\left(f^{n-1} z, f^{n-1} x\right)\right)\right)
\end{aligned}
$$


where

$$
\begin{aligned}
M\left(f^{n-1} z, f^{n-1} x\right) & =\max \left\{d\left(f^{n-1} z, f^{n-1} x\right), d\left(f^{n-1} z, f^{n} z\right), d\left(f^{n-1} x, f^{n} x\right),\right. \\
& \left.\frac{1}{2}\left(d\left(f^{n-1} z, f^{n} x\right)+d\left(f^{n} z, f^{n-1} x\right)\right)\right\} \\
& =\max \left\{d\left(z, f^{n-1} x\right), 0, d\left(f^{n-1} x, f^{n} x\right), \frac{1}{2}\left(d\left(z, f^{n} x\right)+d\left(z, f^{n-1} x\right)\right)\right\} \\
& \left.=\max \left\{d\left(z, f^{n-1} x\right), d\left(z, f^{n} x\right)\right)\right\},
\end{aligned}
$$

for $n$ sufficiently large, because $d\left(\rho^{n-1} x, f^{n} x\right) \rightarrow 0$ when $n \rightarrow \infty$.

Similarly as in the proof of Theorem 2.1, it can be shown that $d\left(z, f^{n} x\right) \leq M\left(z, f^{n-1} x\right)$ $\leq d\left(z, f^{n-1} x\right)$. It follows that the sequence $\left\{d\left(z, f^{n} x\right)\right\}$ is non decreasing and it has a limit $l \geq 0$. Assuming that $l>0$ and passing to the limit in the relation

$$
\psi\left(d\left(z, f^{n} x\right)\right) \leq \psi\left(M\left(z, f^{n-1} x\right)\right)-\varphi\left(\psi\left(M\left(z, f^{n-1} x\right)\right)\right),
$$

one obtain that $l=0$, a contradiction. In the same way it can be deduced that $d(y$, $\left.f^{n} x\right) \rightarrow 0$ as $n \rightarrow \infty$. Now, passing the limit in $d(z, y) \leq d\left(z, f^{n} x\right)+d\left(f^{n} x, y\right)$, it follows that $z=y$ and the uniqueness of the fixed point is proved.

\section{Application to ordinary differential equations}

We prove the existence of solution for the following first-order periodic problem

$$
\begin{aligned}
& u^{\prime}(t)=f(t, u(t)), t \in I=[0, T] \\
& u(0)=u(T),
\end{aligned}
$$

where $T>0$ and $f: I \times \mathbb{R} \rightarrow \mathbb{R}$ is continuous function. Previously, we consider the space $C(I)(I=[0, T])$ of continuous functions defined on $I$. Obviously, this space with metric given by

$$
d(x, y)=\sup \{|x(t)-y(t)|: t \in I\} \text { for } x, y \in C(I)
$$

is a complete metric space. $C(I)$ can also be equipped with partial order given by

$$
x, y \in C(I), x \leq y \Leftrightarrow x(t) \leq y(t) \text { for all } t \in I .
$$

Now, we give the following definition.

Definition 3.1. A lower solution for (3.1) is a function $\alpha \in C^{1}(I)$ such that

$$
\begin{aligned}
& \alpha^{\prime}(t) \leq f(t, \alpha(t)), t \in I=[0, T] \\
& \alpha(0) \leq \alpha(T) .
\end{aligned}
$$

Theorem 3.2. Consider problem (3.1) with $f: I \times \mathbb{R} \rightarrow \mathbb{R}$ continuous and suppose that there exists $\lambda>0$ such that for $x, y \in \mathbb{R}$ with $y \geq x$

$$
0 \leq f(t, y)+\lambda y-[f(t, x)+\lambda x] \leq \frac{\lambda}{2} \ln (y-x+1) .
$$

Then the existence of a lower solution for (3.1) provides the existence of a solution of (3.1).

Proof. Problem (3.1) is equivalent to the integral equation

$$
u(t)=\int_{0}^{T} G(s, t)[f(s, u(s))+\lambda u(s)] d s
$$


where

$$
G(t, s)=\left\{\begin{array}{l}
\frac{e^{\lambda(T+s-t)}}{e^{\lambda T}-1}, 0 \leq s<t \leq T \\
\frac{e^{\lambda(s-t)}}{e^{\lambda T}-1}, 0 \leq t<s \leq T .
\end{array}\right.
$$

Define $F: C(I) \rightarrow C(I)$ by

$$
(F u)(t)=\int_{0}^{T} G(s, t)[f(s, u(s))+\lambda u(s)] d s .
$$

Note that if $u \in C(I)$ is a fixed point of $F$ then $u \in C^{1}(I)$ is a solution of (3.1). Now, we will use Theorem 2.2.

The mapping $F$ is increasing since for $u \geq v$

$$
f(t, u)+\lambda u \geq f(t, v)+\lambda v
$$

using that $G(s, t)>0$ for $(s, t) \in I \times I$, we give

$$
\begin{aligned}
(F u)(t) & =\int_{0}^{T} G(s, t)[f(s, u(s))+\lambda u(s)] d s \\
& \geq \int_{0}^{T} G(s, t)[f(s, v(s))+\lambda v(s)] d s=(F v)(t)
\end{aligned}
$$

for $t \in I$. Besides for $u \geq v$

$$
\begin{aligned}
\ln (d(F(u), & F(v))+1)=\ln \left(\sup _{t \in I}|(F u)(t)-(F v)(t)|+1\right) \\
& =\ln \left(\left[\sup _{t \in I} \int_{0}^{T} G(s, t)[f(s, u(s))+\lambda u(s)]-[f(s, v(s))+\lambda v(s)] d s\right]+1\right) \\
& \leq \ln \left(\left[\sup _{t \in I} \int_{0}^{T} G(s, t) \cdot \frac{\lambda}{2} \ln (u(s)-v(s)+1) d s\right]+1\right) \\
& \leq \ln \left(\left[\frac{\lambda}{2} \cdot \ln (d(u, v)+1) \cdot \sup _{t \in I} \int_{0}^{T} G(s, t) d s\right]+1\right) \\
& \left.\left.=\ln \left(\left[\frac{\lambda}{2} \cdot \ln (d(u, v)+1) \cdot \sup _{t \in I} \frac{1}{e^{\lambda T}-1}\left(\frac{1}{\lambda} e^{\lambda(T+s-t)}\right]_{0}^{t}+\frac{1}{\lambda} e^{\lambda(t-s)}\right]_{t}^{T}\right)\right]+1\right) \\
& =\ln \left(\left[\frac{\lambda}{2} \cdot \ln (d(u, v)+1) \cdot \sup _{t \in I} \frac{1}{\lambda\left(e^{\lambda T}-1\right)} e^{\lambda T}-1\right]+1\right) \\
& =\ln \left(\left[\frac{1}{2} \ln (d(u, v)+1)\right]+1\right) \\
& \leq \ln \left(\left[\frac{1}{2} \ln (M(u, v)+1)\right]+1\right) \\
& =\ln (M(u, v)+1)-\left(\ln (M(u, v)+1)-\ln \left(\left[\frac{1}{2} \ln (M(u, v)+1)\right]+1\right)\right) .
\end{aligned}
$$

Putting $\psi(x)=\ln (x+1)$ and $\varphi(x)=x-\ln \left(\frac{1}{2} x+1\right)$. Obviously $\psi:[0, \infty) \rightarrow[0, \infty)$ is continuous, increasing $\left(\psi^{\prime}(x)=\frac{1}{x+1}>0\right)$, positive in $(0, \infty), \psi(0)=0$ and 
$\lim \sup _{x \rightarrow 0^{+}} \frac{x}{\psi(x)}=1<\infty$. Also, $\phi:[0, \infty) \rightarrow[0, \infty)$ is continuous, positive in $(0, \infty)$ and $\psi(0)=0$, now let $\left\{t_{n}\right\}_{n}$ be sequence that $t_{n} \rightarrow 0$, since $\lim _{n \rightarrow \infty} \frac{\varphi\left(t_{n}\right)}{t_{n}}=\varphi^{\prime}(0)=\frac{1}{2}$, then for $\varepsilon=\frac{1}{4}$, there exists $n_{0}$ such that $\left|\frac{\varphi\left(t_{n}\right)}{t_{n}}-\frac{1}{2}\right|<\frac{1}{4}$, for all $n \geq n_{0}$, hence, $\varphi\left(t_{n}\right) \geq \frac{1}{4} t_{n}$ for all $n \geq n_{0}$.

Therefore the controls function $\psi$ and $\phi$ satisfying the conditions of Theorem 2.2. Finally, if $\alpha(t)$ be a lower solution for (3.1) then we will show that $\alpha \leq F \alpha$.

Indeed

$$
\alpha^{\prime}(t)+\lambda \alpha(t) \leq f(t, \alpha(t))+\lambda \alpha(t), \text { for } t \in I .
$$

Multiplying by $e^{\lambda t}$ we get

$$
\left(\alpha(t) e^{\lambda t}\right)^{\prime} \leq[f(t, \alpha(t))+\lambda \alpha(t)] e^{\lambda t}, \text { for } t \in I
$$

and this gives us

$$
\alpha(t) e^{\lambda t} \leq \alpha(0)+\int_{0}^{t} e^{\lambda s}[f(s, \alpha(s))+\lambda(s)] d s
$$

which implies that

$$
\alpha(0) e^{\lambda T} \leq \alpha(T) e^{\lambda T} \leq \alpha(0)+\int_{0}^{T} e^{\lambda s}[f(s, \alpha(s))+\lambda \alpha(s)] d s
$$

and so

$$
\alpha(0) \leq \int_{0}^{T} \frac{e^{\lambda s}}{e^{\lambda T}-1}[f(s, \alpha(s))+\lambda \alpha(s)] d s .
$$

From this inequality and (3.2), we obtain that

$$
\alpha(t) e^{\lambda t} \leq \int_{0}^{t} \frac{e^{\lambda(T+s)}}{e^{\lambda T}-1}[f(s, \alpha(s))+\lambda \alpha(s)] d s+\int_{t}^{T} \frac{e^{\lambda s}}{e^{\lambda T}-1}[f(s, \alpha(s))+\lambda \alpha(s)] d s
$$

and consequently,

$$
\alpha(t) \leq \int_{0}^{t} \frac{e^{\lambda(T+s-t)}}{e^{\lambda T}-1}[f(s, \alpha(s))+\lambda \alpha(s)] d s+\int_{t}^{T} \frac{e^{\lambda(s-1)}}{e^{\lambda T}-1}[f(s, \alpha(s))+\lambda \alpha(s)] d s .
$$

Hence

$$
\alpha(t) \leq \int_{0}^{T} G(s, t)[f(s, \alpha(s))+\lambda \alpha(s)] d s=(F \alpha)(t)
$$

for $t \in I$. Finally, it follows from Theorems 2.2 that $F$ has a fixed point. 


\section{Acknowledgements}

The authors thank the referees for their valuable comments and suggestions. The third author of this study was partially supported by Basic Science Research Program through the National Research Foundation of Korea (NRF) funded by the Ministry of Education, Science and Technology (Grant No. 2011-0005197).

\section{Author details}

'Department of Mathematics, Semnan University, P.O. Box 35195-363, Semnan, Iran ${ }^{2}$ Department of Mathematics, Semnan University, P.O. Box 35195-363, Semnan, Iran ${ }^{3}$ Department of Mathematics, Kangnam University, Yongin, Gyeonggi 446-702, Korea

\section{Authors' contributions}

All authors read and approved the final manuscript.

\section{Competing interests}

The authors declare that they have no competing interests.

Received: 30 November 2011 Accepted: 18 April 2012 Published: 18 April 2012

\section{References}

1. Alber, Yal, Guerre-Delabrere, S: Principles of weakly contractive maps in Hilbert spaces, new results in operator theory. In: Gohberg, I, Lyubich, Yu (eds.) Advances and Appl, vol. 98, pp. 7-22. Birkhauser Verlag, Basel (1997)

2. Rhoades, BE: Some theorems on weakly contractive maps. Nonlinear Anal. 47, 2683-2693 (2001)

3. Moradi, S, Fathi, Z, Analouee, E: The common fixed point of single-valued gen- eralized $\varphi_{f}$-weakly contractive mappings. Appl Math Lett. 24, 771-776 (2011)

4. Altun, I, Turkoglu, D, Rhoades, BE: Fixed points of weakly compatible maps satisfying a general contractive condition of integral type. Fixed Point Theory and Applications 2007, 9 (2007). Art. ID 17301

5. Djafari Rouhani, B, Moradi, S: Common fixed point of generalized $\varphi_{f}$-weakly contractive multi-valued and single valued mappings. Fixed point theory and Applications 2010, 13 (2010). Art. ID 708984

6. Berinde, V: Approximating fixed points of weak $\varphi$-contractions. Fixed Point Theory. 4, 131-142 (2003)

7. Harjani, J, Sadarangani, K: Fixed point theorems for weakly contractive mappings in partially ordered sets. Nonlinear Anal. 71, 3403-3410 (2009)

8. Cho, YJ, Shah, MH, Hussain, N: Coupled fixed points of weakly F-contractive mappings in topological spaces. Appl Math Lett. 24, 1185-1190 (2011)

9. Zhang, Q, Song, Y: Fixed point theory for generalized $\varphi$-weak contractions. Appl Math Lett. 22, 75-78 (2009)

10. Dorić, D: Common fixed point for generalized $\psi$, $\varphi$-weak contractions. Appl Math Lett. 22, 1896-1900 (2009)

11. Agarwal, RP, El-Gebeily, MA, O'Regan, D: Generalized contractions in partially ordered metric spaces. Appl Anal. 87, 10-116 (2008)

12. Gordji, ME, Ramezani, M: A generalization of Mizoguchi and Takahashis theorem for single-valued mappings in partially ordered metric spaces. Nonlinear Analysis TMA. 74, 4544-4549 (2011)

13. Ciric, L, Cakid, N, Rajovic, M, Uma, JS: Monotone generalized nonlinear contractions in partially ordered metric spaces. Fixed Point Theory and Applications 2008, 11 (2008). Art. ID 131294

14. Nieto, JJ, Rodriguez-López, R: Contractive mapping theorems in partially ordered sets and applications to ordinary differential equations. Order. 22, 223-239 (2005)

15. Nieto, JJ, Pouso, RL, Rodriguez-López, R: Fixed point theorems in ordered abstract spaces. Proc Am Math Soc. 135, 2505-2517 (2007)

16. O'Regan, D, Petrusel, A: Fixed point theorems for generalized contractions in ordered metric spaces. J Math Anal Appl. 341(2):1241-1252 (2008)

17. Petrusel, A, Rus, IA: Fixed point theorems in ordered L-spaces. Proc Am Math Soc. 134, 411-418 (2006)

18. Cho, YJ, Rhoades, BE, Saadati, R, Samet, B, Shantawi, W: Nonlinear coupled fixed point theorems in ordered generalized metric spaces with integral type. Fixed Point Theory Appl. 2012, 8 (2012)

19. Cho, YJ, Saadati, R, Wang, S: Common fixed point theorems on generalized distance in order cone metric spaces. Comput Math Appl. 61, 1254-1260 (2011)

20. Graily, E, Vaezpour, SM, Saadati, R, Cho, YJ: Generalization of fixed point theorems in ordered metric spaces concerning generalized distance. Fixed Point Theory Appl. 2011, 30 (2011)

21. Sintunavarat, W, Cho, YJ, Kumam, P: Common fixed point theorems for c-distance in ordered cone metric spaces. Comput Math Appl. 62, 1969-1978 (2011)

22. Cho, YJ, He, G, Huang, NJ: The existence results of coupled quasi-solutions for a class of operator equations. Bull Korean Math Soc. 47, 455-465 (2010)

23. Abbas, M, Cho, YJ, Nazir, T: Common fixed point theorems for four map- pings in TVS-valued cone metric spaces. J Math Inequal. 5, 287-299 (2011)

24. Nieto, JJ, Rodriguez-López, R: Existence and uniqueness of fixed point in partially ordered sets and applications to ordinary differential equations. Acta Math Sinica. 23, 2205-2212 (2007)

25. Ran, ACM, Reurings, MCB: A fixed point theorem in partially ordered sets and some applications to matrix equations. Proc Am Math Soc. 132, 1435-1443 (2004)

26. Nieto, JJ, Rodriguez-López, R: Existence of extremal solutions for quadratic fuzzy equations. Fixed Point Theory Appl. 2005, 321-342 (2005)

27. Nieto, JJ, Rodriguez-López, R: Applications of contractive-like mapping principles to fuzzy equations. Rev Mat Complut. 19, 361-383 (2006)

28. Eshaghi Gordji, M, Baghani, H, Cho, YJ: Coupled fixed point theorems for contractions in intuitionistic fuzzy normed spaces. Math Comput Model. 54, 1897-1906 (2011) 
29. Burgic, Dz, Kalabusic, S, Kulenovic, MRS: Global attractivity results for mixed monotone mappings in partially ordered complete metric spaces. Fixed Point Theory Appl 2009, 17 (2009). Art. ID 762478

30. Gnana Bhaskar, T, Lakshmikantham, V: Fixed points theorem in partially ordered metric spaces and applications. Nonlinear Anal. 65, 1379-1393 (2006)

31. Lakshmikantham, V, Ciric, L: Coupled fixed point theorems for nonlinear contractions in partially ordered metric spaces. Nonlinear Anal. 70, 4341-4349 (2009)

32. Wu, Y: New fixed point theorems and applications of mixed monotone operator. J Math Anal Appl. 341, 883-893 (2008)

doi:10.1186/1687-1812-2012-62

Cite this article as: Gordji et al:: Common fixed point theorems for $(\psi, \phi)$-weak nonlinear contraction in partially ordered sets. Fixed Point Theory and Applications 2012 2012:62.

Submit your manuscript to a SpringerOpen ${ }^{\circ}$ journal and benefit from:

- Convenient online submission

- Rigorous peer review

- Immediate publication on acceptance

- Open access: articles freely available online

- High visibility within the field

- Retaining the copyright to your article

Submit your next manuscript at $\boldsymbol{s p r i n g e r o p e n . c o m ~}$ 